\title{
ENTRE DESRESPEITO E RECONHECIMENTO: AS COMUNIDADES QUILOMBOLAS DE SÃO ROQUE E RIO DO MEIO (IVAÍ, 1990-2016)
}

Raphael Pagliarini ${ }^{1}$

RESUMO: Este artigo busca compreender o processo de constituição das comunidades quilombolas de São Roque e do Rio do Meio, situadas no município de Ivaí, Sudeste do Paraná, entre os anos de 1990 e 2015, a partir do diálogo com a teoria do reconhecimento social desenvolvida por Axel Honneth. Desta forma, problematizará as relações estabelecidas entre os negros e os demais grupos étnicos-sociais estabelecidos na região, entre os quais, alemães, poloneses e ucranianos. Fundamentalmente, objetiva-se pensar as possíveis situações de desrespeito sofridas pelos negros e as formas como reagiram a elas. Neste sentido, a análise das fontes produzidas pelos quilombolas, permitirá a problematização dessa luta por reconhecimento, que dentre outras maneiras, se materializou na constituição legal e prática das comunidades estudadas. Através da trajetória de sujeitos individuais e coletivos, buscarse-á entender como as relações intersubjetivas, internas e externas ao grupo, resultaram no reconhecimento das comunidades por parte do Estado.

Palavras-chave: Comunidades quilombolas; desrespeito; reconhecimento; Paraná.

\section{BETWEEN DISRESPECT AND RECOGNITION: THE QUILOMBOLA COMMUNITIES OF SÃO ROQUE AND RIO DO MEIO (IVAÍ, 1990-2016)}

\begin{abstract}
This article aims to understand the process of constituting the quilombola communities of São Roque and Rio do Meio, located in the municipality of Ivaí, Southeast of Paraná, between 1990 and 2015, based on the dialogue with the theory of social recognition developed by Axel Honneth. In this way, will problematize the established relations between the blacks and the other ethnic-social groups established in the region, among them, germans, poles and ukrainians. Fundamentally, it aims to think about the possible situations of disrespect suffered by blacks and the ways in which they responded to them. In this sense, the analysis of the sources produced by the quilombolas, will allow the problematization of this struggle for recognition, that among other ways, materialized in the legal and practical constitution of the studied communities. Through the trajectory of individual and collective subjects, it will be sought to understand how intersubjective relations, internal and external to the group, resulted in the recognition of the communities by the State.
\end{abstract}

Keywords: Quilombola communities; disrespect; recognition; Paraná.

\section{ENTRE DESRESPEITO Y RECONOCIMIENTO: LAS COMUNIDADES QUILOMBOLAS DE SAN ROQUE Y RIO DEL MEDIO (IVAÍ, 1990-2016).}

RESUMEN: Este artículo busca comprender el proceso de constitución de las comunidades quilombolas de São Roque y del Río del Medio, situadas en el distrito de Ivaí, Sudeste de Paraná, entre los años 1990 y 2015, a partir del diálogo con la teoría del reconocimiento social

\footnotetext{
${ }^{1}$ Doutorando em História pela Universidade Federal do Paraná (UFPR). Técnico em Assuntos Educacionais do Instituto Federal do Paraná (IFPR). E-mail: raphaelpagliarini@ yahoo.com.br
} 
desarrollada por Axel Honneth. De esta forma, problematizará las relaciones establecidas entre los negros y los demás grupos étnicos-sociales establecidos en la región, entre ellos, alemanes, polacos y ucranianos. Fundamentalmente, se objetiva pensar las posibles situaciones de falta de respeto sufridas por los negros y las formas en que reaccionan a ellas. En este sentido, el análisis de las fuentes producidas por los quilombolas, permitirá la problematización de esa lucha por reconocimiento, que de entre otras maneras, se materializó en la constitución legal y práctica de las comunidades estudiadas. Por medio de la trayectoria de sujetos individuales y colectivos, se buscará entender cómo las relaciones intersubjetivas, internas y externas al grupo, resultaron en el reconocimiento de las comunidades por parte del Estado.

Palabras clave: Comunidades quilombolas; falta de respeto; reconocimiento; Paraná.

São Roque e Rio do Meio são duas das 3018 comunidades remanescentes de quilombo $^{2}$ reconhecidas pelo governo brasileiro através da Fundação Cultural Palmares. Localizadas no município de Ivaí, região sudeste do estado do Paraná, compõem o conjunto de 37 comunidades situadas em território paranaense. A primeira carrega o nome do seu santo padroeiro. A segunda, ao identificar uma de suas características geográficas, leva o nome do rio que atravessa sua área. Duas comunidades distintas, porém, que compartilham grande parte de suas memórias e histórias.

Para entender a presença dos negros na região é necessário considerar o processo de ocupação dos chamados Campos Gerais. Diretamente relacionada ao crescimento do mercado interno nacional, principalmente em decorrência da exploração das Minas Gerais, a região em questão passou a receber mão-de-obra no intuito de desenvolver as atividades agropecuárias (LOPES, 2004). ${ }^{3}$ Caracterizada por pastagens de qualidade, não tardou para que tivesse seus campos ocupados por gado vacum.

As atividades pecuárias assumem uma nova característica com a abertura dos caminhos que interligavam São Paulo ao Rio Grande do Sul. Após a abertura do chamado Caminho de Viamão, na década de trinta do século XVIII, a produção de gado gaúcha se sobrepôs à da região. A partir de então, estas terras passaram a ser utilizadas como área de

\footnotetext{
${ }^{2}$ Segundo o Decreto $\mathrm{N}^{\circ} 4.887 / 2003$, são as comunidades formadas por grupos étnico-raciais, segundo critérios de auto-definição, com trajetória histórica própria, dotados de relações territoriais específicas, com presunção de ancestralidade negra relacionada com a resistência à opressão histórica sofrida.

${ }^{3}$ No livro Fazendas e sítios de Castro e Carambeí (2004), José Carlos Veiga Lopes faz um levantamento documental de grande parte das propriedades que hoje compõem a região dos Campos Gerais. Seu período de análise se inicia em 1704, ano em que a primeira sesmaria é expedida em nome do capitão Pedro Taques de Almeida, e segue até 1855 .
} 
paragens e engorda para os animais que seguiam em direção às feiras de Sorocaba (IANNI, 1962). Além do gado, as mulas também se destacavam como importantes animais que seguiam às regiões mineradoras. Criadas exclusivamente pelos estanceiros do Rio Grande do Sul, a locação de pastagens para abrigar os muares tornou-se um dos principais negócios para os fazendeiros dos campos gerais (MACHADO, 1962).

É nesta situação que ocorre a intensificação do uso da mão de obra escrava na região, e embora não se disponha de documentos que demonstrem o momento de chegada dos descendentes dos atuais moradores das comunidades estudadas, podemos pensá-lo de maneira relacionada a este contexto.

Em 1836, o número de fazendas nos distritos de Castro, Curitiba e Lapa, era de 88. Ao lado desses latifúndios surgiram inúmeros pequenos sítios. Situavam-se em terras das fazendas, ao lado destas, ao longo das estradas, nas proximidades das vilas. Eram propriedades de gente pobre. Alguns desses sítios eram trabalhados também por escravos, e seus proprietários eram agregados das fazendas, capatazes, libertos, gente de trabalho manual. Criavam alguns cavalos e vacas, plantavam milho e feijão, que negociavam com os tropeiros que vinha do sul. (Idem, p.136).

Dada a recente emancipação política do município de Ivaí, julho de 1961, faz-se necessário uma breve retrospectiva política para demonstrar a relação existente entre ele e o município de Castro. Ainda em meados do século XIX desmembraram-se do território de Castro o município de Ponta Grossa. No final do mesmo século, parte desta região da origem ao município de Ipiranga, que por fim, tem parte de sua porção leste transformada no município de Ivaí. Nesse sentido, os relatos sobre as propriedades e práticas existentes em Castro estão relacionados à região hoje ocupada por São Roque e Rio do Meio.

Assim como no caso dos negros escravizados, a vinda dos imigrantes europeus à região dos campos gerais, em meados do século XIX, também está vinculada à necessidade de abastecimento do mercado interno. No primeiro caso, como dito anteriormente, o objetivo era atender a demanda gerada pela região de Minas Gerais. No segundo, atribuiu-se aos novos trabalhadores, dentre outras expectativas, a capacidade de suprir o abastecimento do próprio estado. Apesar de alguns núcleos de colonização datarem de um período anterior à emancipação política do Paraná $(1853)^{4}$, foi a partir dela que se intensificou a instalações de colônias organizadas sob a chancela do estado.

\footnotetext{
${ }^{4}$ No período anterior à emancipação política do estado foram fundadas três colônias. A primeira, localizada em Rio Negro, foi fundada em 1829 e recebeu imigrantes alemães. Quase duas décadas mais tarde (1847), sob
}

Fronteiras: Revista de História | Dourados, MS | v. 19 | n. 34 | p. 389 - 404 | Jul. / Dez. 2017 
Se considerarmos as motivações econômicas para a entrada de imigrantes no estado, perceberemos projetos distintos de colonização no Paraná após sua emancipação. O primeiro deles ficou a cargo do governo estadual e resultou na implantação de um conjunto de núcleos coloniais entre os anos de 1860 e 1880. Altiva Pilatti Balhana classifica essa primeira fase como "imigração para criar agricultura de abastecimento" (1996). Segundo ela, o fato de a província ter sua economia pautada no abastecimento de um mercado externo, seja pela produção da erva-mate, seja pela criação de gado e invernada de mulas nos campos gerais, gerou uma escassez interna de produtos agrícolas. Sendo assim, as colônias foram organizadas no intuito de produzir alimentos, diminuindo dessa forma a necessidade de importação por parte da província. Identifica-se nessa situação, por exemplo, as colônias instaladas próximas à cidade de Curitiba, que tinham entre os seus principais objetivos, além de uma produção que garantisse o autossustento, o abastecimento da capital. Com este mesmo intuito, novas colônias foram estabelecidas tanto no litoral como na região dos campos gerais. Porém, sem que atingissem a mesma prosperidade econômica daquelas localizadas próximas à capital.

Ainda segundo a autora (BALHANA et al. 1969), uma nova proposta caracterizou a colonização pós 1880 . Com uma menor participação oficial, o objetivo agora era fornecer mão-de-obra às grandes obras públicas. A construção de estradas de rodagem, e principalmente, de ferrovias, demandaram um grande número de trabalhadores. A vinda desses imigrantes foi potencializada pelas chamadas "sociedades de imigração". Criadas em onze localidades distintas, essas associações "atuaram de modo eficiente e variado na promoção de serviços de imigração, inclusive na propaganda das terras do Paraná para a colonização" (Idem, p.183).

Todavia, esse processo de formação de colônias ficou paralisado por praticamente uma década. Imerso nos conflitos da chamada Revolução Federalista, seu serviço de imigração foi suspenso e retomado apenas em 1907. Neste ano, três novas colônias, agora denominadas colônias federais, foram implantadas no Paraná. A mais numerosa delas foi a Colônia Federal do Ivay. A partir de dados dos Relatórios de Presidente da Província, estimase que 4840 imigrantes se instalaram nos núcleos de Calmon e São Roque, hoje município de

liderança do médico francês João Maurício Faivre, foi fundada a Colônia Thereza. Composta por imigrantes franceses, situa-se hoje no município de Cândido Abreu. Por fim, em 1852, foi fundada a colônia de Superagui, atualmente pertencente ao município de Guaraqueçaba. 
Ivaí. Uma população constituída majoritariamente por ucranianos, além de poloneses e alemães (Idem, p.167).

A chegada dos imigrantes foi vista de diferentes maneiras, de acordo com aquele que a observava. Para o governo do estado, tratava-se de mais uma colônia instalada no interior do seu território; para os próprios imigrantes, um momento em que o novo pautava tanto expectativas como desafios; por fim, para os negros que ocupavam aquela região, o estabelecimento de um novo grupo com quem passaram a conviver nas mais diversas esferas do cotidiano. Um grupo que trazia não apenas novos costumes, mas que se instalava ali com o aval do estado, tendo dessa maneira o reconhecimento legal das terras adquiridas.

As diferentes condições em que negros e brancos chegaram à região influenciou de maneira direta os espaços ocupados por cada um deles. Tanto em relação às terras, como nas múltiplas esferas políticas de poder, os primeiros foram preteridos em detrimento aos imigrantes. Mesmo que a presença dos negros tenha antecedido os demais grupos, isso não garantiu o seu reconhecimento pelo poder público local. O predomínio do poder político dos descendentes dos europeus, majoritariamente dos ucranianos, pode ser percebido na própria memória material construída na cidade. A imagem abaixo, publicada na página da Prefeitura Municipal, ilustra o momento de inauguração de um dos monumentos que fazem referência à presença ucraniana. Como se pode notar, à frente da obra encontram-se autoridades políticas e religiosas do município. Cultura e poder aparecem de forma sobrepostas.

Figura 01 - Monumento à Pessanka Inaugurado em Ivaí

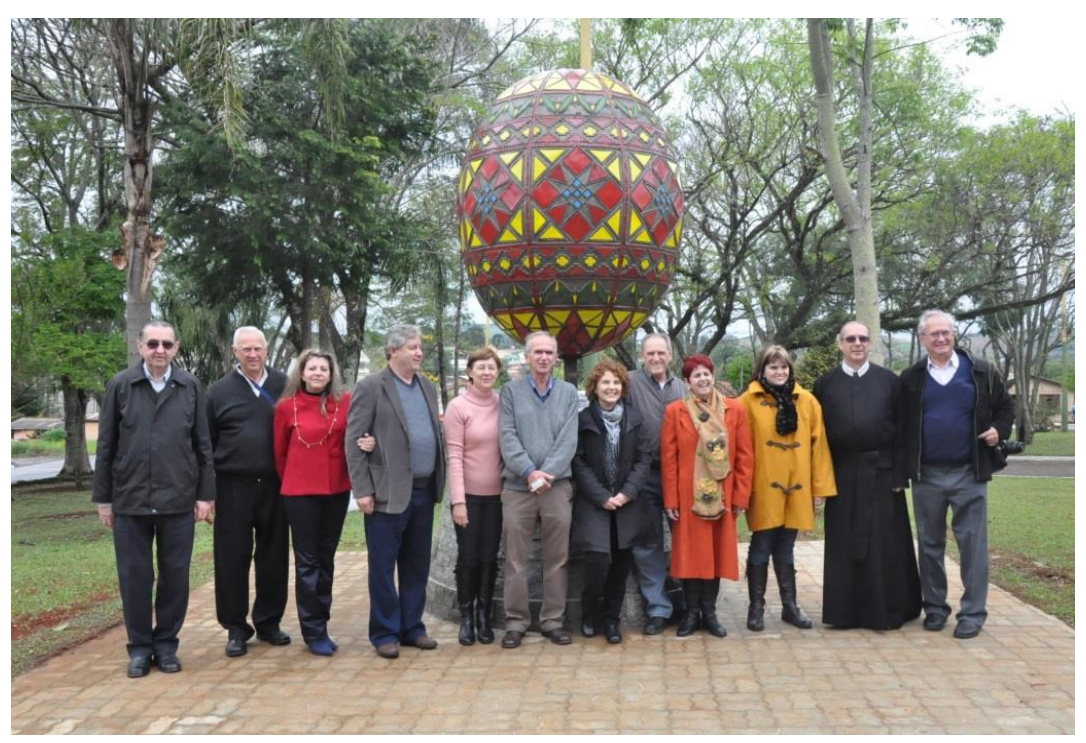

Fonte: Página da Prefeitura Municipal de Ivaí (http://ivai.pr.gov.br/index.php?sessao=9f97bbd817sp9f\&id $=480$

Fronteiras: Revista de História | Dourados, MS |v. 19 | n. 34 | p. 389 - 404 | Jul. / Dez. 2017 
Seguindo na página oficial da Prefeitura, agora no espaço destinado à "História" do município, temos outro exemplo em que a presença ucraniana é considerada em detrimento às demais. Após apresentar alguns dados geopolíticos, e enfatizar os princípios de justiça, igualdade e transparência, que segundo o texto caracterizam o governo, segue com um poema:

\author{
Poema dedicado a Ivaí \\ Um lugar onde o povo materializou a cultura \\ Em sofisticados detalhes da arquitetura \\ Seus templos demonstram sua força religiosa \\ Que brota desta gente amiga e calorosa \\ Da terra forte e das mãos calejadas \\ Vem o progresso desta cidade amada \\ Toalha bordada, fartura na mesa \\ Em suas cachoeiras ilustre beleza \\ Nas faces humanas \\ Os traços da cultura ucraniana \\ Dos estrangeiros fostes terra preferida \\ Dos brasileiros tão querida \\ Símbolo de união em sua bandeira \\ Cidade tranquila, mas hospitaleira \\ Felicidade e sucesso moram aqui \\ No meu Paraná, na cidade de Ivaí \\ (Anderson Gibathe) $^{5}$
}

Podemos destacar neste texto, pelo menos dois elementos de apelo a uma presença branca, nomeadamente os de origem ucraniana. O primeiro deles, posto de maneira mais sutil, faz referência à "toalha bordada", símbolo do folclore construído pelos migrantes que chegaram ao Brasil em fins do século XIX. Logo em seguida, o posicionamento é mais direto: "Nas faces humanas/os traços da cultura ucraniana". Ao publicar o poema no site oficial da Prefeitura, no link "história de Ivaí”, fica clara a intenção da administração pública de reforçar uma "origem" ucraniana do município.

É importante ressaltar que não se trata de um questionamento acerca da importância que este ou aquele grupo exerceu sobre a produção econômica do município, ou mesmo, o quão representativo numericamente ele é ou tenha sido, argumentos geralmente utilizados para respaldar estes atos de distinção. Mas sim, busca-se entender como estes e outros elementos alimentam um discurso de afirmação de grupo, permitindo inclusive, que ao ocuparem os espaços políticos oficiais, se inscrevam na história como únicos protagonistas. No estudo em questão, devemos pensar ucranianos e quilombolas, e aqui a diversidade interna

\footnotetext{
${ }^{5}$ Disponível em: http://ivai.pr.gov.br/index.php?sessao=46094782eanc46\&id=1200 Acesso em: $11 \mathrm{de}$ fev. de 2017.
}

Fronteiras: Revista de História | Dourados, MS |v. 19 | n. 34 | p. 389 - 404 | Jul. / Dez. 2017 
de ambos os grupos deve sempre ser considerada, sob pena de incorrer em perigosas generalizações, como sujeitos que disputam espaços de reconhecimento. Obviamente, é preciso evidenciar que se trata de uma relação desigual de poder.

Na obra intitulada Luta por reconhecimento: a gramática moral dos conflitos sociais (2003), Axel Honneth retoma os escritos do "jovem Hegel” e atribui a ele um papel de precursor no campo da chamada teoria do reconhecimento social. Apesar de ratificar as várias críticas ao pensamento de Hegel, principalmente no que tange a sua leitura metafísica, defende que seus escritos são extremamente importantes para pensar essas questões na sociedade moderna. Da mesma forma, as etapas apresentadas por Hegel, em que as relações de amor, direito e eticidade (solidariedade) permitem aos indivíduos se confirmarem de maneira recíproca como pessoas "autônomas e individuais", são também problematizadas.

Demasiadamente idealista para fazer frente às teorias histórico-materialistas de seus sucessores, o pensamento hegeliano recebeu em Honneth uma "inflexão materialista". Esse revisionismo se deu basicamente por uma apropriação da psicologia social de George Herbert Mead. Como escreveu o autor: Com os meios construtivos da psicologia social de Mead foi possivel dar à teoria hegeliana da "luta por reconhecimento" uma inflexão "materialista" (Idem, p.155). A partir dessa aproximação dos autores, Honneth elabora uma "teoria social de teor normativo" baseada nas relações intersubjetivas construídas entre o sujeito (eu) e os seus parceiros de interações (outros).

A reprodução da vida social se efetua sob o imperativo de um reconhecimento recíproco porque os sujeitos só podem chegar a uma autorrelação prática quando aprendem a se conceber, da perspectiva normativa de seus parceiros de interação, como seus destinatários sociais. No entanto, uma tese relevante para a explicação disso só resulta dessa premissa geral se nela é incluído um elemento dinâmico: aquele imperativo ancorado no processo da vida social opera como uma coerção normativa obrigando os indivíduos à uma deslimitação gradual do conteúdo do reconhecimento recíproco, visto que só por esse meio eles podem conferir uma expressão social às pretensões de sua subjetividade que sempre se regeneram (Idem, 2003, p. 154-155).

Dois eixos complementares se destacam no trecho acima. O primeiro deles diz respeito à interação existente no processo de reconhecimento. Pois, o sujeito, seja ele individual ou coletivo, só assumirá uma postura ativa se reconhecer a existência do outro. É 
frente ao meu destinatário que construo o meu espaço de reconhecimento. Em seguida, enfatiza-se também a dinamicidade presente nessas ações. Característico do pensamento hegeliano, a noção de movimento deve ser entendida como um resultado infindável dessas interações.

Sendo assim, cabe apresentar os sujeitos negligenciados pelos registros até aqui apresentados, e que a partir de um determinado momento passaram a ver os demais grupos como seus destinatários. Incialmente ocupantes de uma única propriedade, os moradores de São Roque e Rio do Meio não conseguem, ou ainda, não tiveram a preocupação, de precisar o período de chegada de seus descendentes à região. Imersos em uma tradição oral, alguns dos moradores mais velhos, como o Sr. Hamilton Ferreira de Lima, relatam sobre a migração interna da Bahia para o Paraná. Todavia, como é possível perceber em sua fala, outros negros já ocupavam esse espaço há muito tempo.

Eu nasci no Rio do Meio (...). É que, aqui, São Roque e Rio do Meio, era um terreno só, compreende? Era um terreno dos Ferreiras, antigos.

Era uma família dona de tudo $?^{6}$

É, era dona de tudo essa parte aqui como vai até a divisa de Ipiranga (...). Eles eram donos né. Não eram os que moravam, eram dono de terra! Os Ferreira passaram pra turma de lá! É no tempo que, no tempo que veio a imigração de estrangeiro. Compreende? Quando, quando, que eles eram dos apostos, dos como diz...? Esse mais velhos que eu tô falando, vieram do... Daquele tempo de... Ah, desses que trabalhavam, como é que é...? Vocês sabem dizer, eu não sei... Da escravidão (...). O tal de Paulo Ferreira que era nosso parente. E esse então, quando minha vó veio da Bahia, que minha vó era baiana, despojado pela escravidão né? Então quando ela veio da Bahia esse homem já tava que não tinha dente quase pra comer, de velho (risos) (...). Era o tal do Paulo Ferreira.

Que era o dono de tudo?

O dono dessa terra aí. Daí ele picou e deixou essa igreja aqui pra nós, pro pessoal do... Daqui de roda, que tinha os morador né.

E a vó, a vó do senhor veio da Bahia?

A minha vó era Baiana.

Veio pra trabalhar aqui pros Ferreira?

Ela veio soltada, desse jeito dos Ferreira, e veio vindo pra cá né (risos).

Aham. Não era fazenda de escravos aqui?

Não.

O pessoal era livre?

Escravos vieram de certo pra cá né (LIMA, 2013).

Pelas memórias do Sr. Hamilton, o passado não se estende para além de duas gerações antecedentes. A vinda da avó do estado da Bahia aparece como um marco na

\footnotetext{
${ }^{6}$ Os trechos em itálico correspondem as perguntas feitas pelo entrevistador.
} 
trajetória familiar. Todavia, a noção de família se expande quando se refere à posse das terras. Segundo ele, seus parentes eram os "donos" das terras hoje ocupadas pelos "estrangeiros". Na figura abaixo, podemos visualizar a distribuição geográfica das duas comunidades em relação ao território do município. A considerável proximidade entre elas corrobora o argumento do entrevistado de se tratar inicialmente de uma única propriedade. Argumento que também se reforça quando se avalia as relações de parentescos existentes entre seus moradores.

Figura 02 - Comunidades Quilombolas no Município de Ivaí

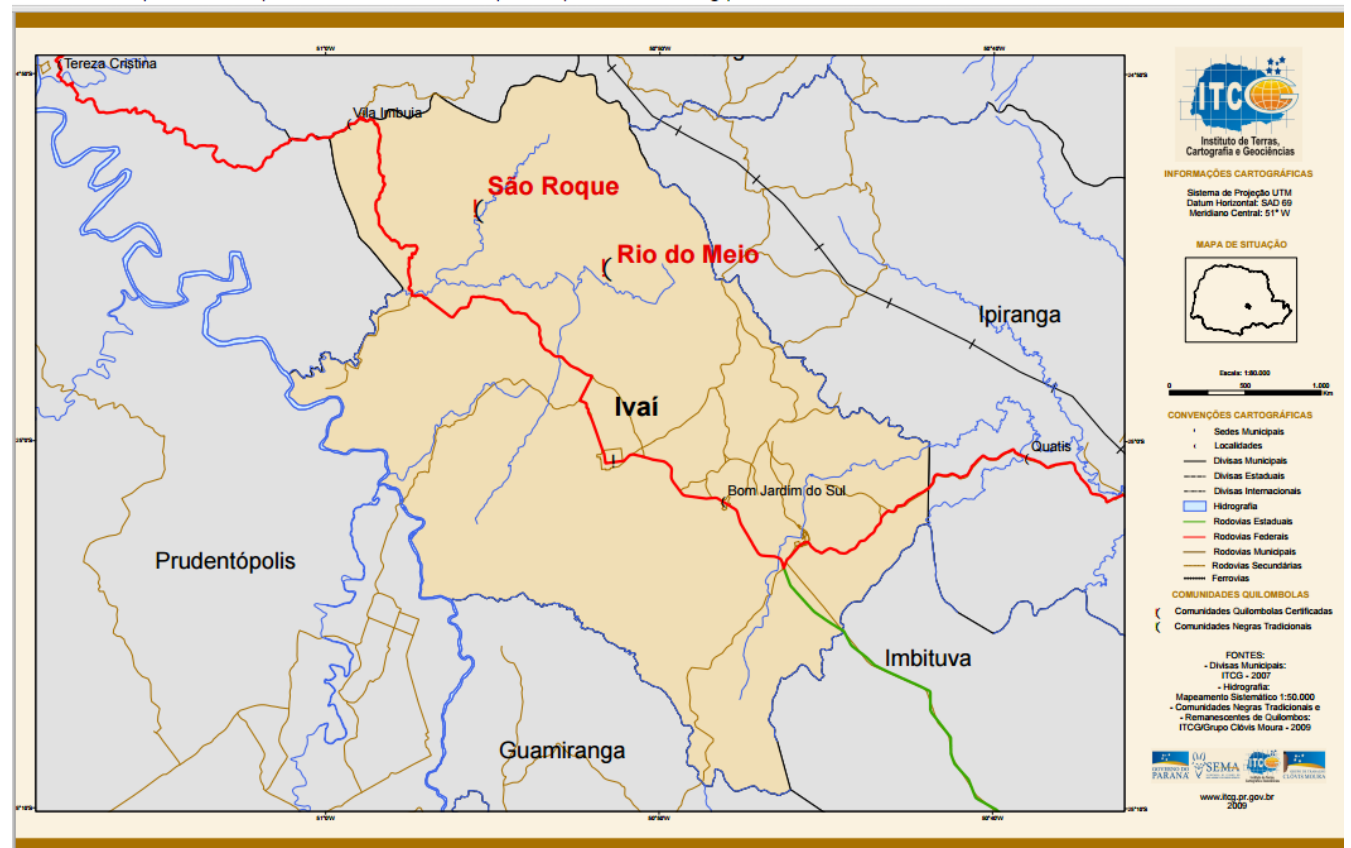

Fonte: Instituto de Terras Cartografias e Geociências: ITCG $^{7}$

Apesar de algumas diferenças entre as duas comunidades, a luta para serem reconhecidos como quilombolas ocorreu no mesmo período. Com vinte e duas famílias cadastradas, e pouco mais de oitenta habitantes, os moradores do Rio do Meio se valeram, dentre outros argumentos, de um documento escrito para "comprovarem" suas origens "quilombolas". Uma carta redigida por uma das moradoras da comunidade, provavelmente no início da década de 1990, sintetizava a "história do grupo". A autora da carta, hoje falecida, foi durante muitos anos a professora da escola existente na comunidade, e seus escritos ganharam um ar de autenticação daquela identidade. Intitulada "O Início do Rio do Meio",

\footnotetext{
${ }^{7}$ Disponível em: http://www.itcg.pr.gov.br/arquivos/File/quilombolas 2009/IVAI.pdf Acesso em: 18 de fev. de 2017.
} 
trazia em seu conteúdo aspectos referentes à chegada do grupo na região, além de práticas cotidianas:

Foi assim em 13 de maio de 1888 deu-se a libertação dos escravos que era uma vergonha no Brasil. Quem trabalhou para libertar os escravos foi Princesa Isabel e Euzebio de Queiroz. Os donos desses escravos não esbanjaram eles. Esses escravos eram da África e da bahia, os seus donos vieram com animal com calgueiro, esses calgueiros que vinham com alimento os cesto chamava-se bruaca, os cesto era feito de couro de caças grande como anta e outros. Vieram fazendo picada até aqui e deu a cada um dos escravos um lote para trabalharem, e deram o nome de Rio do Meio (sic) $[\ldots]^{8}$.

No trecho transcrito acima, nota-se a incorporação de um discurso oficial de libertação dos escravos. Figuras como Princesa Isabel e Euzébio de Queiros são citadas como as principais responsáveis por esse processo. Da mesma forma, torna-se clara a reinvindicação de um "pioneirismo" negro sobre a região: para chegarem até ali, "vieram fazendo picada". Por fim, um apelo ao direito a terra, ao lote que receberam antes mesmo de denominarem a região como Rio do Meio.

Todas essas informações nos contam muito mais do período em que se produziu o documento do que daquele da chegada dos primeiros negros. O passado é utilizado como um instrumento de luta no presente. Ao se colocarem como "pioneiros", buscam um reconhecimento tanto das suas necessidades materiais, nesse caso a posse da terra, como simbólicas, terem sua presença reconhecida na história daquela região. Em suma, uma luta por reconhecimento.

Em um olhar mais distanciado, podemos notar pelo menos a existência de dois interlocutores em um mesmo espaço, a saber, negros e brancos. Ao aproximarmos as lentes, outra denominação parece mais coerente, quilombolas e ucranianos. Conforme apresentado acima, o reconhecimento destes assumiu uma força incomparável em relação aos quilombolas. Retomando os escritos de Honneth:

Visto que o conteúdo de semelhantes interpretações depende por sua vez de qual grupo social consegue interpretar de maneira pública as próprias realizações e formas de vida como particularmente valiosas, aquela práxis exegética secundária não pode ser entendida senão com conflito cultural de longa duração: nas sociedades modernas, as relações de estima social estão sujeitas a uma luta permanente na qual os diversos grupos procuram elevar, com os meios da força simbólica e em referência às finalidades gerais, o

\footnotetext{
${ }^{8}$ A autoria do documento é atribuída a Maria Cândida Ferreira de Lima e foi transcrita conforme o original.
}

Fronteiras: Revista de História | Dourados, MS |v. 19 | n. 34 | p. 389 - 404 | Jul. / Dez. 2017 
valor das capacidades associadas à sua forma de vida (HONNETH, 2003, p. 207).

Não resta dúvida de que a "forma de vida" dos ucranianos se difundiu em Ivaí como o modelo valioso. A estima social assumida pelo grupo contribuiu no processo de difusão de uma maneira característica de se viver. Aos negros, a possibilidade de ação e organização enquanto grupo se deu de maneira mais enfática a partir dos últimos anos, e se colocou pelo apelo à identidade quilombola.

De acordo com a teoria de Axel Honneth, a simples existência dos sujeitos/grupos não garante a luta por reconhecimento. Para tal, é necessário que haja uma ação de desrespeito, que essa seja entendida enquanto tal pelo grupo desrespeitado, e finalmente, que ela motive uma reação, ou seja, uma busca por reconhecimento. Três categorias distintas de desrespeito são apresentadas pelo autor: a tortura (violação do corpo); a privação de diretos (exclusão social); e por fim, a degradação da honra, ou do status do indivíduo ou do grupo. Na história dos moradores de São Roque e Rio do Meio, todas elas se fizeram ou fazem presentes de uma maneira ou de outra. (Idem, p. 214).

Tratada como "a espécie mais elementar de rebaixamento pessoal” (Idem, p.215), a tortura foi elemento constituinte das relações escravocratas, ainda que não tenha se extinguido com o fim deste regime. De acordo com o autor, as lesões físicas sofridas extrapolam a dor corporal, pois constituem um sentimento de estar sujeito à vontade de um outro. Perda de confiança em si e no mundo, além de um sentimento de vergonha social, são apontados como consequências desse desrespeito. Possivelmente, nenhum daqueles moradores foi diretamente submetido a essa condição. Entretanto, a memória sobre a escravidão se relaciona diretamente com ela. Afinal, alguns acontecimentos assumem uma proporção tão grande no imaginário coletivo de um grupo, que algumas pessoas sentem como se os tivessem vivenciado. (POLLAK, 1992, p. 02).

Se a tortura não foi vivenciada diretamente pelos atuais moradores das comunidades quilombolas, o mesmo não se pode dizer da exclusão social. Fruto de uma privação de direitos, esta forma de desrespeito se faz presente cotidianamente naqueles espaços. Em relação a essa forma de desrespeito, escreveu Honneth:

Portanto, o que aqui é subtraído da pessoa pelo desrespeito em termos de reconhecimento é o desrespeito cognitivo de uma imputabilidade de moral que, por seu turno, tem de ser adquirida a custo em processos de interação socializadora. Mas essa forma de desrespeito representa uma grandeza historicamente variável, visto que o conteúdo semântico do que é 
considerado como uma pessoa moralmente imputável tem se alterado com o desenvolvimento das relações jurídicas: por isso, a experiência da privação de direitos se mede não somente pelo grau de universalização, mas também pelo alcance material dos direitos institucionalmente garantidos (2003, p. 217).

Agindo diretamente no campo da moral, esta forma ataca a possibilidade de autorrespeito do sujeito. Da mesma maneira, como escreveu o autor, é preciso estar atento ao fato de se tratar de uma "grandeza historicamente variável". Só haverá privação de um direito desde que ele esteja institucionalmente garantido. A posse da terra, como vimos anteriormente, encaixa-se perfeitamente nesse exemplo. Pois, apesar de ser constitucionalmente garantido como um direito, não foi titulada em nome dos moradores.

Por fim, em relação à terceira categoria de desrespeito, temos o rebaixamento do modo de vida, da estima social do grupo. Trata-se de "negar aos sujeitos atingidos a possibilidade de atribuir um valor social às suas próprias capacidades” (Idem, p.217). As discussões anteriormente desenvolvidas acerca do predomínio da valorização dos ucranianos em detrimento aos quilombolas apontam nessa direção.

Distintas entre si, as três formas de desrespeito carregam o potencial de desencadear um movimento de reação. Apesar de em algumas situações políticas e culturais, a possibilidade de se colocar contra a ação desrespeitosa seja muito limitada, em outras ela alimenta uma luta intensa. Como vimos, no caso dos negros em questão, essa luta por reconhecimento se canalizou pela bandeira quilombola.

Praticamente invisíveis aos olhos do estado republicano, os quilombolas garantiram o seu reconhecimento legal apenas na Constituição Federal de 1988. Também fruto das ações dos movimentos negros, fortalecidas nas décadas de 1970 e 1980, parte das reivindicações dos moradores das comunidades remanescentes de quilombo foi registrada no texto constitucional. O Art. 68 das disposições constitucionais transitórias estabelece uma importante garantia: "Aos remanescentes das comunidades dos quilombos que estejam ocupando suas terras é reconhecida a propriedade definitiva, devendo o Estado emitir-lhes os títulos respectivos"9

Discutido por estudiosos das diversas áreas das ciências humanas, o conceito de quilombo deve ser pensado de maneira plural e dinâmica. Se durante a escravidão foram também espaços de concentração de escravos fugitivos, com o fim do regime essa situação se

\footnotetext{
${ }^{9}$ BRASIL. Constituição da República Federativa do Brasil. Brasília, DF: Senado Federal: Centro Gráfico, 1998.
} 
modificou. Principalmente no período pós-abolição, houve a constituição de um grande número de comunidades formadas por escravos libertos e seus descendentes. Ocupando principalmente terras devolutas, estes negros estabeleciam novos espaços de vivência e sociabilidades (O'DWYER, 2002).

O grande desafio, tanto por parte daqueles que normatizavam a questão jurídica, como dos que buscavam seus direitos, era saber o que significava ser quilombola. Coube ao Decreto 4887, de 20 de novembro de 2003, que regulamenta o procedimento para identificação, reconhecimento, delimitação, demarcação e titulação das terras ocupadas por remanescentes das comunidades dos quilombos de que trata o art. 68 do Ato das Disposições Constitucionais Transitórias, estabelecer em seu art. $2^{\circ}$ :

Consideram-se remanescentes das comunidades dos quilombos os grupos étnico-raciais, segundo critérios de auto-definição, com trajetória histórica própria, dotados de relações territoriais específicas, com presunção de ancestralidade negra relacionada com a resistência à opressão histórica sofrida. (BRASIL, 2008).

A partir da definição legal do conceito de comunidade quilombola, inicia-se o processo de certificação. Como se pode perceber, o decreto respeitou a multiplicidade de experiências que caracterizam as comunidades quilombolas do país. Ainda que coubesse ao Estado, por meio da Fundação Cultural Palmares, certificar as comunidades, a autodefinição foi posta como critério fundamental. Foi a partir desse entendimento de autodefinição, que comunidades negras de quase todas as regiões do Paraná incorporaram o "quilombola" em suas denominações.

Em nível local, os documentos produzidos pelos moradores apresentam importantes elementos para pensar tanto a organização dos grupos como os conflitos identitários por eles vivenciados. As atas de constituição das associações das comunidades permitem entendermos um pouco sobre a construção desse processo de reconhecimento. Em São Roque, parte dos seus 203 habitantes formou sua associação em meados de 2007.

Aos onze dias do mês de junho de dois mil e sete, quatorze horas, na sede da Comunidade do Quilombo de São Roque, Município de Ivaí - Estado do Paraná. Com a presença das famílias moradoras do quilombo, conforme assinatura constantes do livro de presença em Assembleias Gerais a mesa foi composta pela Comissão Provisória de Constituição da Associação: Sr. Nelson Lourenço, Sra. Irene Ribeiro Ferreira, Sr. Joelceo Lourenço e Sr. Hamilton Ferreira de Lima, pelos convidados: Secretário da Agricultura e Meio Ambiente, Sr. Paulo Kalatai, o Gerente da Agência do Banco do Brasil 
Sr. Haroldo de Castro e a Gerente da Cooperativa Sicredi Sra. Kellyn Cristiane Munsberg de Souza, Professora Terezinha Beatriz Pavlak e pela funcionária do Instituto da Emater Sra. Gilma de Farias Zimmer assessora de Organização Rural. (Ata de Constituição da Associação, 2007).

Para além do comparecimento dos moradores locais, cabe sublinhar os chamados "convidados": três servidores públicos e dois gerentes bancários. A presença destas pessoas no ato não pode ser entendida apenas como pro forma. Trata-se, antes de tudo, de uma ação de reconhecimento do grupo por parte de representantes do poder político e econômico.

Sabe-se que parte dos moradores de São Roque e Rio do Meio assumiu uma identidade de remanescente de quilombo, e o fez na medida em que submeteu uma autodeclaração à Fundação Cultural Palmares. Mas esta não foi uma escolha única, nem mesmo excluiu outras possíveis. Exemplo disso, são as denominações dadas às associações de moradores por eles constituídas. Em ambos os casos, não há uma referência ao quilombo, mas à identidade negra. Foram denominadas Associação da Comunidade Negra de São Roque e Associação da Comunidade Negra de Rio do Meio.

Ao nominarem as associações, os moradores não apenas cumprem um ato formal de registro, mas exprimem suas identificações. Expressam claramente a importância de se dizerem negros, ainda que a política em vigor os tratasse como remanescentes de quilombo. Em meio a um conjunto possíveis de escolhas, reforçam a questão racial. Os até então moradores das comunidades de São Roque e Rio do Meio demarcam através da cor suas diferenças em relação ao conjunto das demais comunidades do município. Com isso, fazem aquilo que a historiadora brasileira Hebe Mattos chamou de quebra do pacto de silêncio:

No Brasil, nomear a cor ainda hierarquiza, pois implica quebrar o pacto de silêncio sobre o passado escravo, celebrado entre os cidadãos brasileiros livres em plena vigência da escravidão. Passados mais de cem anos da Abolição, quebrar com a ética do silêncio apresenta-se paradoxalmente como caminho possível para reverter tal processo de hierarquização cristalizado no tempo, e instaurar um universalismo almejado, mas não verdadeiramente atingido, desde o século passado (MATTOS, 2005-2006, p.111).

A autodefinição e a posterior constituição das associações das comunidades foram passos iniciais de um processo ainda em curso. Apesar de a Constituição Federal garantir aos remanescentes dos quilombos, ainda em 1988 (BRASIL, 1988), o direito à propriedade 
definitiva das terras por eles ocupadas, a titulação dessas terras em nome das comunidades é extremamente morosa. Entre os anos de 2005 e 2016, o INCRA emitiu apenas 86 títulos de terras em nome das comunidades ${ }^{10}$.

No caso de Ivaí, os processos abertos pelo INCRA datam de 2009. Desde então, quase nada foi feito. Segundo os autos dos processos, nem mesmo a intervenção do Ministério Público tornou o andamento mais célere. Os quase dez anos desde a autodefinição como remanescentes de quilombo, e a longa espera pela ação do estado foi avaliada de maneira distinta nas comunidades. Os moradores de São Roque, em assembleia coordenada por representantes do INCRA, decidiram dar continuidade no processo de titulação das terras. Já em Rio do Meio, optaram por paralisar o processo. Certamente que outros fatores influenciaram nessas decisões, que de todo modo, não são necessariamente definitivas.

Desde a chegada dos primeiros imigrantes à região de Ivaí, os moradores das comunidades de São Roque e Rio do Meio se viram diante de novos problemas. O desequilíbrio de poder, característico das relações estabelecidas entre brancos e negros em sociedades racistas, produziu inúmeras formas de desrespeito. Como resposta a esta condição, ações que visavam reconhecimento foram pautadas pelos negros em diferentes momentos. $\mathrm{Na}$ última década, esta busca por reconhecimento se deu principalmente pela adesão à proposta quilombola. Ao se declararem remanescentes de quilombos, os moradores não apenas reivindicavam à titulação das terras que seriam suas por direito, mas também passaram a exigir respeito pela história do grupo.

\section{FONTE ORAL}

LIMA, Hamilton Ferreira. Entrevista gravada em 05 de abril de 2013. São Roque - Ivaí/PR.

\section{REFERÊNCIAS BIBLIOGRÁFICAS}

BRASIL. Constituição (1988). Constituição da República Federativa do Brasil. Brasília, DF: Senado Federal: Centro Gráfico, 1998.

Decreto 4887, de 20 de novembro de 2003. Regulamenta o procedimento para identificação, reconhecimento, delimitação, demarcação e titulação das terras ocupadas por remanescentes das comunidades dos quilombos de que trata o art. 68 do Ato das Disposições Constitucionais Transitórias. Brasília, DF, 2003.

\footnotetext{
10 Disponível em: http://www.incra.gov.br/sites/default/files/incra-andamentoprocessosquilombolas_quadrogeral.pdf. Acesso em 13 de nov. de 2017.
}

Fronteiras: Revista de História | Dourados, MS | v. 19 | n. 34 | p. 389 - 404 | Jul. / Dez. 2017 
BALHANA, Altiva Pilatti. Política Imigratória do Paraná. Revista Paraná. Desenvolvimento, Curitiba, v. n.87, p.39-50, jan/abr., 1996.

\section{Grafipar, 1969.}

HONNETH, Axel. Luta por reconhecimento: A gramática moral dos conflitos sociais. São Paulo: Editora 34, 2003.

IANNI, Octavio. As metamorfoses do escravo: apogeu e crise da escravatura no Brasil Meridional. São Paulo: Difel, 1962.

IVAÍ. Ata de Constituição da Associação de Moradores. Comunidade Remanescente de Quilombo de São Roque, 2007.

LOPES, José Carlos Veiga. Fazendas e sítios de Castro e Carambeí. Curitiba: Torre de Papel, 2004.

MACHADO, Brasil Pinheiro. Contribuição ao estudo da história agrária do Paraná: formação da estrutura agrária tradicional dos Campos Gerais. Anais do II Simpósio Nacional dos Professores Universitários de História, pp. 129-155, 1962.

MAPAS. Comunidades Quilombolas no Município de Ivaí. Curitiba: Instituto de Terras, Cartografia e Geociências, 2009.

MATTOS, Hebe. "Remanescentes das comunidades dos quilombos": memória do cativeiro e políticas de reparação no Brasil. REVISTA USP, São Paulo, n.68, p. 104-111, dezembro/fevereiro 2005-2006.

O'DWYER, Eliane Cantarino (org.). Quilombos. Identidade étnica e territorialidade. Rio de Janeiro: Editora FGV, 2002.

POLLAK, Michael. Memória e identidade social. Estudos Históricos. Rio de Janeiro, v. 5, n.10, 1992, p. 200-212. 